\title{
Allocating value among farsighted players in network formation
}

\section{Nicolas CARAYOL}

$\&$

\section{Rémi DELILLE}

GREThA, CNRS, UMR 5113

Université de Bordeaux

$\&$

Vincent VANNETELBOSCH

CORE

Université de Louvain

\&

CEREC

Saint-Louis university

Cahiers du GREThA

$$
n^{\circ} \text { 2014-05 }
$$

February

\author{
GRETHA UMR CNRS 5113 \\ Université Montesquieu Bordeaux IV \\ Avenue Léon Duguit - 33608 PESSAC - FRANCE \\ Tel : +33 (0)5.56.84.25.75 - Fax : +33 (0)5.56.84.86.47 - www.gretha.fr
}


Formation de réseaux avec agents "farsighted" : une règle d'allocation.

\title{
Résumé
}

Nous proposons un concept d'étude de la stabilité des réseaux sociaux économiques lorsque les joueurs anticipent les répercutions de leurs actions sur la dynamique des réseaux ("Farsighted players") et que la règle d'allocation est endogène. Un ensemble de réseaux est de type "Von Neumann-Morgenstern farsightedly stable (VMFS) dans un cadre de négociation s'il existe une règle d'allocation et un point de menace tels que : ( $i$ ) il n'existe pas de chemin d'amélioration "farsighted " d'un réseau à l'intérieur de l' ensemble vers un autre réseau à l'intérieur de l'ensemble, (ii) à partir de n'importe quel réseau en dehors de I'ensemble, il existe un chemin d'amélioration "farsighted " qui retourne à l'intérieur de I' ensemble, (iii) la valeur générée par chaque réseau est répartie entre les joueurs de manière à ce qu'ils bénéficient ou souffrent égalitairement d'être liés deux à deux comparativement au paiement qu'ils obtiendraient à leur point de menace crédible respectif. Nous montrons que l'ensemble des réseaux efficients est l'unique ensemble de type VFMS si la règle d'allocation est anonyme et efficiente en composant et la richesse générée par les réseaux est top convex. En outre, la règle d'allocation égalitaire en composants émerge de manière endogène.

Mots-clés : Joueurs farsighted, Stabilité, Egalité des pouvoirs de négociation.

Allocating value among farsighted players in network formation

\begin{abstract}
We propose a concept to study the stability of social and economic networks when players are farsighted and allocations are determined endogenously. A set of networks is a von Neumann-Morgenstern farsightedly stable set with bargaining if there exists an allocation rule and a bargaining threat such that (i) there is no farsighted improving path from one network inside the set to another network inside the set, (ii) from any network outside the set there is a farsighted improving path to some network inside the set, (iii) the value of each network is allocated among players so that players suffer or benefit equally from being linked to each other compared to the allocation they would obtain at their respective credible bargaining threat. We show that the set of strongly efficient networks is the unique von Neumann-Morgenstern farsightedly stable set with bargaining if the allocation rule is anonymous and component efficient and the value function is top convex. Moreover, the componentwise egalitarian allocation rule emerges endogenously.
\end{abstract}

Keywords: Farsighted players, Stability, Equal bargaining power

JEL: A14; C70; D20

Reference to this paper: CARAYOL Nicolas, DELILLE Rémi, VANNETELBOSCH Vincent (2014) Allocating value among farsighted players in network formation, Cahiers du GREThA, n²014-05.

http://ideas.repec.org/p/grt/wpegrt/2014-05.html. 


\section{Introduction}

The organization of agents into networks and groups plays an important role in the determination of the outcome of many social and economic interactions. ${ }^{1}$ A simple way to analyze the networks that one might expect to emerge in the long run is to examine the requirement that players do not benefit from altering the structure of the network. An example of such a condition is the pairwise stability notion defined by Jackson and Wolinsky (1996). A network is pairwise stable if no player benefits from severing one of her links and no two players benefit from adding a link between them. Pairwise stability is a myopic definition. Players are not farsighted in the sense that they do not forecast how others might react to their actions. For instance, the adding or severing of one link might lead to subsequent addition or severing of another link. If players have very good information about how others might react to changes in the network, then these are things one wants to allow for in the definition of the stability concept. For instance, a network could be stable because players might not add a link that appears valuable to them given the current network, as that might in turn lead to the formation of other links and ultimately lower the payoffs of the original players.

Allocation rules keep track of how value is allocated among the players in the network. The allocation rule may simply be the utility that players directly get, accounting for the costs and benefits of being linked to other players in the network. But there are many situations where the allocation rule is the result of some bargaining among linking players. However, most network formation models are such that both the network formation process and the allocation of value among players in a network are separated and the players are not farsighted.

In this paper we address the question of which networks one might expect to emerge in the long run when the players are farsighted and the allocation of value among players is determined simultaneously with the network formation as players may bargain over their shares of value within their component. Hence, we introduce the notion of von Neumann-Morgenstern farsighted stability with bargaining.

A set of networks is a von Neumann-Morgenstern farsightedly stable set with bargaining if there exists an allocation rule and a bargaining threat such that (i) there is no farsighted improving path from one network inside the set to another

\footnotetext{
${ }^{1}$ See Jackson $(2003,2008)$, or Goyal (2007) for a comprehensive introduction to the theory of social and economic networks.
} 
network inside the set, ${ }^{2}$ (ii) from any network outside the set there is a farsighted improving path to some network inside the set, (iii) the value of each network is allocated among players so that players suffer or benefit equally from being linked to each other compared to the allocation they would obtain at their respective credible bargaining threat. In contrast to Chwe's (1994) definition of von NeumannMorgenstern farsighted stability, ${ }^{3}$ allocations are going to be agreed upon among farsighted players when allocations and links are determined jointly. To capture this idea we request that the allocation rule satisfy the property of equal bargaining power for farsighted players. This property requires that, for each pair of players linked in the network, both players suffer or benefit equally from being linked with respect to their respective bargaining threat. In addition, we request the bargaining threat to be credible. Credibility means that the threat can be reached by a farsighted improving path emanating from some network adjacent to the network over which bargaining takes place.

We show that the set of strongly efficient networks is the unique von NeumannMorgenstern farsightedly stable set with bargaining if the allocation rule is anonymous and component efficient and the value function is anonymous, component additive and top convex. Moreover, the componentwise egalitarian allocation rule emerges endogenously.

We next incorporate the property of equal bargaining power for farsighted players into the original definition of a pairwise farsightedly stable set due to Herings, Mauleon and Vannetelbosch (2009). ${ }^{4}$ We find that if a set of networks is a von Neumann-Morgenstern farsightedly stable set with bargaining, then it is a pairwise farsightedly stable set with bargaining. Hence, if the allocation rule is anonymous and component efficient and the value function is anonymous, component additive and top convex, then the set of strongly efficient networks is a pairwise farsightedly stable set with bargaining where the componentwise egalitarian allocation rule emerges endogenously. However, the set of strongly efficient networks $E(v)$ can also

\footnotetext{
${ }^{2} \mathrm{~A}$ farsighted improving path is a sequence of networks that can emerge when players form or sever links based on the improvement the end network offers relative to the current network. Each network in the sequence differs by one link from the previous one.

${ }^{3}$ Mauleon, Vannetelbosch and Vergote (2011) have provided the characterization of von Neumann-Morgenstern farsightedly stable sets in one-to-one matching problems and in manyto-one matching problems with substitutable preferences.

${ }^{4}$ Other approaches to farsightedness in network formation are Herings, Mauleon, and Vannetelbosch (2004), Page, Wooders and Kamat (2005), Dutta, Ghosal, and Ray (2005), and Page and Wooders (2009).
} 
be a pairwise farsightedly stable set with bargaining even for anonymous allocation rules where the value of each component is not shared equally among the members of the component. If the value function is not top convex, then inefficient networks can be farsightedly stable with bargaining. We provide an example where, contrary to pairwise farsighted stability with bargaining, von Neumann-Morgenstern farsighted stability with bargaining only leads to the emergence of inefficient networks.

There are a number of papers that look at the endogenous determination of allocations together with network formation. Currarini and Morelli (2000) have introduced a sequential network formation game, where players propose links and demand allocations. Given an exogenously given order, each player proposes in turn the links she wants to form and she demands an allocation. Once all proposals have been made, links are formed if both players involved in the link have proposed the link and the demands of the players are compatible (i.e. demands do not exceed the value produced). They have shown that, if the value function satisfies size monotonicity (i.e. if the efficient networks connect all players), then their sequential network formation process with endogenous allocations leads all subgame perfect equilibrium to be efficient. ${ }^{5}$ Mutuswami and Winter (2002) have proposed subscription mechanisms for network formation when the costs from linking are publicly known but the benefits from linking are not known to the social planner. Their mechanism is similar to Currarini and Morelli (2000) sequential network formation game $^{6}$ and leads to the formation of an efficient network. ${ }^{7}$ The payoffs in Currarini and Morelli (2000) and Mutuswami and Winter (2002) are endogenously generated but are highly asymmetric and sensitive to the order in which players make proposals. More recently, Bloch and Jackson (2007) have studied the role played by transfers payments in the formation of networks. They have investigated whether different forms of transfers (direct transfers, indirect transfers or contingent transfers) can solve the conflict between stability and efficiency when there are network externalities that usually lead to the emergence of inefficient networks when trans-

\footnotetext{
${ }^{5}$ However, if the network formation process is simultaneous, then there are value functions that satisfy size monotonicity for which inefficient equilibria can arise.

${ }^{6}$ Each player, when it is her turn, proposes the set of links she wants to form and her cost contribution. Once all proposals have been made, the social planner selects the network to be formed and the cost contributions of the players.

${ }^{7}$ Slikker and van den Nouweland (2000) have studied the formation of communication networks with endogenous payoff division but with a strategic form game. Similarly, Matsubayashi and Yamakawa (2004) have proposed a strategic form game to share the cost of building the network in a model where the benefits of the network decays as the distance among players increases.
} 
fers are not feasible. ${ }^{8}$ But all these papers have assumed either simultaneous move games (with myopic players) or sequential move games (with finite horizon and specific ordering). We go further by looking at the endogenous determination of payoffs together with network formation in presence of farsighted players.

The paper most closely related to our work is Navarro (2013a) who has studied a dynamic process of network formation that is represented by means of a stationary transition probability matrix. Forward-looking players have a common discount factor and receive payoffs at each moment in time according to a stationary allocation rule. Three properties are imposed on the allocation rule and the transition probability. First, the allocation rule together with the transition probability are expected fair. That is, for each link in the network both players involved in the link benefit or suffer the same stream of discounted expected payoffs from cutting their link at time zero. Second, the allocation rule is component efficient. That is, the value of each component is shared among the members of the component. Third, the expected fair allocation rule and transition probability is a pairwise network formation procedure. That is, the probability that a link is added (or deleted) is positive only if the stream of discounted expected payoffs for the players involved in adding (or deleting) the link is positive. Navarro (2013a) has shown that if the common discount factor is small enough (i.e. players are close to be myopic), then there exists an allocation rule together with a transition probability matrix such that the allocation rule is component efficient and the allocation rule together with the transition probability is an expected fair pairwise network formation procedure. ${ }^{9}$

Here, we rather adopt the stability approach because the noncooperative or dynamic approach is much sensitive to the specification of the bargaining game and network formation process, whose fine details (such as how the game ends) can be very important in determining what networks form and how value is allocated.

The paper is organized as follows. In Section 2 we introduce some notations, basic properties and definitions for networks. In Section 3 we define the notion of von Neumann-Morgenstern farsighted stability with bargaining and we look at the relationship between von Neumann-Morgenstern farsighted stability with bar-

\footnotetext{
${ }^{8}$ They have found that indirect transfers together with contingent transfers are needed to guarantee that efficient networks form. Indirect transfers enable players to take care of positive externalities by subsidizing the formation of links by other players; while contingent transfers enable players to overcome negative externalities by preventing the formation of links

${ }^{9}$ Navarro (2013b) has used her dynamic network formation process and her solution concept to investigate the tension between efficiency and stability.
} 
gaining and efficiency of networks. In Section 4 we propose the notion of pairwise farsighted stability with bargaining and we look at its relationship with the von Neumann-Morgenstern farsighted stability with bargaining. In Section 5 we discuss some properties. In particular, we address situations where there are externalities across components and we provide a condition such that the set of efficient networks remains the unique von Neumann-Morgenstern farsightedly stable set with bargaining. In Section 6 we conclude.

\section{Networks, values and allocation rules}

\section{Networks}

Let $N=\{1, \ldots, n\}$ be the finite set of players who are connected in some network relationship. The network relationships are reciprocal and the network is thus modeled as a non-directed graph. Players are the nodes in the graph and links indicate bilateral relationships between players. Thus, a network $g$ is simply a list of which pairs of individuals are linked to each other. We write $i j \in g$ to indicate that $i$ and $j$ are linked under the network $g$. Let $g^{S}$ be the set of all subsets of $S \subseteq N$ of size $2 .{ }^{10}$ So, $g^{N}$ is the complete network. The set of all possible networks or graphs on $N$ is denoted by $\mathbb{G}$ and consists of all subsets of $g^{N}$. The network obtained by adding link $i j$ to an existing network $g$ is denoted $g+i j$ and the network that results from deleting link $i j$ from an existing network $g$ is denoted $g-i j$. Let $\left.g\right|_{S}=\{i j \mid i j \in g$ and $i \in S, j \in S\}$. Thus, $\left.g\right|_{S}$ is the network found deleting all links except those that are between players in $S$. For any network $g$, let $N(g)=\{i \mid \exists j$ such that $i j \in g\}$ be the set of players who have at least one link in the network $g$. The neighborhood of player $i$ is the set of players that $i$ is linked to: $N_{i}(g)=\{j \mid i j \in g\}$. A network $g^{\prime}$ is adjacent to $g$ if $g^{\prime}=g+i j$ or $g^{\prime}=g-i j$ for some $i j$. Let $A(g)$ be the set of adjacent networks to $g$. Let $A_{i}(g)=\left\{g^{\prime} \in A(g) \mid \# N_{i}\left(g^{\prime}\right) \neq \# N_{i}(g)\right\}$.

A path in a network $g \in \mathbb{G}$ between $i$ and $j$ is a sequence of players $i_{1}, \ldots, i_{K}$ such that $i_{k} i_{k+1} \in g$ for each $k \in\{1, \ldots, K-1\}$ with $i_{1}=i$ and $i_{K}=j$, and such that each player in the sequence $i_{1}, \ldots, i_{K}$ is distinct. A non-empty network $h \subseteq g$ is a component of $g$, if for all $i \in N(h)$ and $j \in N(h) \backslash\{i\}$, there exists a path in $h$ connecting $i$ and $j$, and for any $i \in N(h)$ and $j \in N(g), i j \in g$ implies $i j \in h$. The set of components of $g$ is denoted by $C(g)$. Let $\Pi(g)$ denote the partition of

\footnotetext{
${ }^{10}$ Throughout the paper we use the notation $\subseteq$ for weak inclusion and $\varsubsetneqq$ for strict inclusion. Finally, \# will refer to the notion of cardinality.
} 
$N$ induced by the network $g$. That is, $S \in \Pi(g)$ if and only if either there exists $h \in C(g)$ such that $S=N(h)$ or there exists $i \notin N(g)$ such that $S=\{i\}$.

\section{Value functions}

A value function is a function $v$ that assigns a value $v(S, g)$ to every network $g$ and every coalition $S \in \Pi(g)$. This value $v(S, g)$ can be perfectly distributed among the players in $S$. Given $v$, the total value that can be distributed at network $g$ is equal to $v(g)=\sum_{S \in \Pi(g)} v(S, g)$. The set of all possible value functions $v$ is denoted by $\mathcal{V}$. A value function $v$ is component additive (or has no externalities across components) (Jackson and Wolinksky, 1996) if for any $g \in \mathbb{G}$ and $S \in \Pi(g)$, $v(S, g)=v\left(S,\left.g\right|_{S}\right)$. Component additivity means that the value of a component of the network does not depend on the structure of the network outside the component. Given a permutation of players $\pi$ and any $g \in \mathbb{G}$, let $g^{\pi}=\{\pi(i) \pi(j) \mid i j \in g\}$. Thus, $g^{\pi}$ is a network that is identical to $g$ up to a permutation of the players. A value function $v$ is anonymous (Jackson and Wolinsky, 1996) if for any permutation $\pi$, $g \in \mathbb{G}$ and $S \in \Pi(g), v\left(\{\pi(i) \mid i \in S\}, g^{\pi}\right)=v(S, g)$. A network $g \in \mathbb{G}$ is strongly efficient relative to $v$ if $v(g) \geq v\left(g^{\prime}\right)$ for any $g^{\prime} \in \mathbb{G}$. Let $E(v)$ be the set of strongly efficient networks. A value function $v$ is top convex (Jackson and van den Nouweland, 2005) if some strongly efficient network maximizes the per capita value among players. Let $\rho(v, S)=\max _{g \subseteq g^{S}} v(g) / \# S$. The value function $v$ is top convex if $\rho(v, N) \geq \rho(v, S)$ for any $S \subseteq N$.

\section{Allocation rules}

An allocation rule $y$ is a function that assigns a payoff $y_{i}(g, v)$ to player $i \in N$ from graph $g$ under the value function $v \in \mathcal{V}$. An allocation rule $y$ is component efficient (Myerson, 1977) if for any $g \in \mathbb{G}$ and $S \in \Pi(g), \sum_{i \in S} y_{i}(g, v)=v(S, g) \cdot{ }^{11}$ Given a permutation $\pi$, let $v^{\pi}$ be defined by $v^{\pi}(S, g)=v\left(\left\{\pi^{-1}(i) \mid i \in S\right\}, g^{\pi^{-1}}\right)$ for any $g \in \mathbb{G}$. An allocation rule $y$ is anonymous (Jackson and Wolinsky, 19996) if for any $v, g \in \mathbb{G}$ and permutation $\pi, y_{\pi(i)}\left(g^{\pi}, v^{\pi}\right)=y_{i}(g, v)$.

Some prominent allocation rules have been proposed. The egalitarian allocation rule (Jackson and Wolinsky, 1996) $y^{e}$ is defined by $y_{i}^{e}(g, v)=v(g) / n$. For a component additive $v$ and network $g$, the componentwise egalitarian allocation rule (Jackson and Wolinsky, 1996) $y^{c e}$ is such that for any $S \in \Pi(g)$ and each $i \in S$, $y_{i}^{c e}(g, v)=v\left(S,\left.g\right|_{S}\right) / \# S$. For a $v$ that is not component additive, $y^{c e}(g, v)=v(g) / n$ for all $g$; thus, $y^{c e}$ splits the value $v(g)$ equally among all players if $v$ is not component

\footnotetext{
${ }^{11}$ An allocation rule $y$ is component balanced (Jackson and Wolinsky, 1996) if for any component additive $v, g \in \mathbb{G}$ and $S \in \Pi(g), \sum_{i \in S} y_{i}(g, v)=v\left(S,\left.g\right|_{S}\right)$.
} 
additive.

Another allocation rule is the Myerson value:

$$
\left.y_{i}^{M V}(g, v)=\sum_{S \subseteq N \backslash\{i\}} v\left(\left.g\right|_{S \cup\{i\}}\right)-v\left(\left.g\right|_{S}\right)\right)\left(\frac{\# S !(n-\# S-1) !}{n !}\right) .
$$

An allocation rule satisfies equal bargaining power if for any component additive $v$ and $g \in \mathbb{G}$ we have $y_{i}(g, v)-y_{i}(g-i j, v)=y_{j}(g, v)-y_{j}(g-i j, v)$. Equal bargaining power requires that both players equally benefit or suffer from the addition of the link. It does not impose that players split the marginal value of a link. Jackson and Wolinsky (1996) have shown that $y$ satisfies component balance and equal bargaining power if and only if $y(g, v)=y^{M V}(g, v)$ for all $g \in \mathbb{G}$ and component additive $v .^{12}$ However, Jackson (2005) has argued that the basic problem with the Myerson value allocation rule is that the value of other possible networks is not properly accounted for in its calculations. For instance, if alternative network structures are taken into account when bargaining over how to allocate value, then values of alternative networks, and not just (adjacent) subnetworks, should be important in determining the allocation. Hence, Jackson (2005) has proposed the player-based flexible network allocation rule: ${ }^{13}$

$$
y_{i}^{P B F N}(g, v)=\frac{v(g)}{\widehat{v}\left(g^{N}\right)} \sum_{S \subseteq N \backslash\{i\}}\left(\widehat{v}\left(g^{S \cup\{i\}}\right)-\widehat{v}\left(g^{S}\right)\right)\left(\frac{\# S !(n-\# S-1) !}{n !}\right),
$$

where $\widehat{v}$ is the monotonic cover of $v$ defined by $\widehat{v}=\max _{g^{\prime} \subseteq g} v\left(g^{\prime}\right) .{ }^{14}$ However, the player-based flexible network allocation rule rule violates both equal bargaining power and component balance. ${ }^{15}$ We now provide an example that illustrates the drawbacks of the Myerson value and the player-based flexible network allocation rule. This example also motivates the necessity of determining the allocation rule together with the formation of the network in the long run.

Example 1 The Myerson value. Take $N=\{1,2,3\}$ and the value function defined by $v(\{1,2,3\},\{12,13,23\})=0, v(\{1,2,3\},\{12,13\})=5, v(\{1,2,3\},\{12,23\})=$

\footnotetext{
${ }^{12}$ Navarro (2007) has proposed a component efficient and fair allocation rule when the value of the network can exhibit any type of externalities across its components.

${ }^{13}$ Perez-Castrillo and Wettstein (2005) have proposed a sequential mechanism whose subgame perfect equilibria rise to strongly efficient networks and to payoffs that coincide with Jackson's player-based flexible network allocation rule.

${ }^{14}$ The monotonic cover of a value function gives the highest value that can be generated by building a network out of a given set of links.

${ }^{15}$ Navarro (2010) has proposed three modifications of Jackson's (2005) flexible network axiom when the structure of externalities across components is known.
} 
$v(\{1,2,3\},\{13,23\})=0, v(\{1,2\},\{12\})=v(\{3\},\{12\})=0, v(\{1,3\},\{13\})=$ $v(\{2\},\{13\})=0, v(\{2,3\},\{23\})=4, v(\{1\},\{23\})=0$, and $v(S, \emptyset)=0$. We have depicted in Figure 1 the different network configurations with their associated allocations. For networks that generate value, the Myerson value leads to equal sharing of the value in $\{12,13\}, y_{i}^{M V}(\{12,13\})=5 / 3$ for $i \in N$. Hence, players 2 and 3 obtain less than what they could get in $\{23\}$, namely $y_{2}^{M V}(\{23\})=2=y_{3}^{M V}(\{23\})$. Players 2 and 3 have a viable outside option but the Myerson value does not take this option into account because $\{23\}$ is not a subnetwork of $\{12,13\}$. The player-based flexible network allocation rule provides a more reasonable allocation than the Myerson value for $\{12,13\}$ by giving higher allocations to players 2 and 3 than player 1 : $y_{2}^{M V}(\{12,13\})=7 / 3=y_{3}^{M V}(\{12,13\})$ and $y_{1}^{M V}(\{12,13\})=1 / 3$. However, it gives $y_{2}^{P B F N}(\{23\})=28 / 15=y_{3}^{P B F N}(\{23\})$ and $y_{1}^{P B F N}(\{23\})=4 / 15$ violating component balance. Hence, this allocation is unlikely to emerge at $\{23\}$ since the value function is component additive and players 2 and 3 transfer some payoff to player 1 who does not belong to their component.
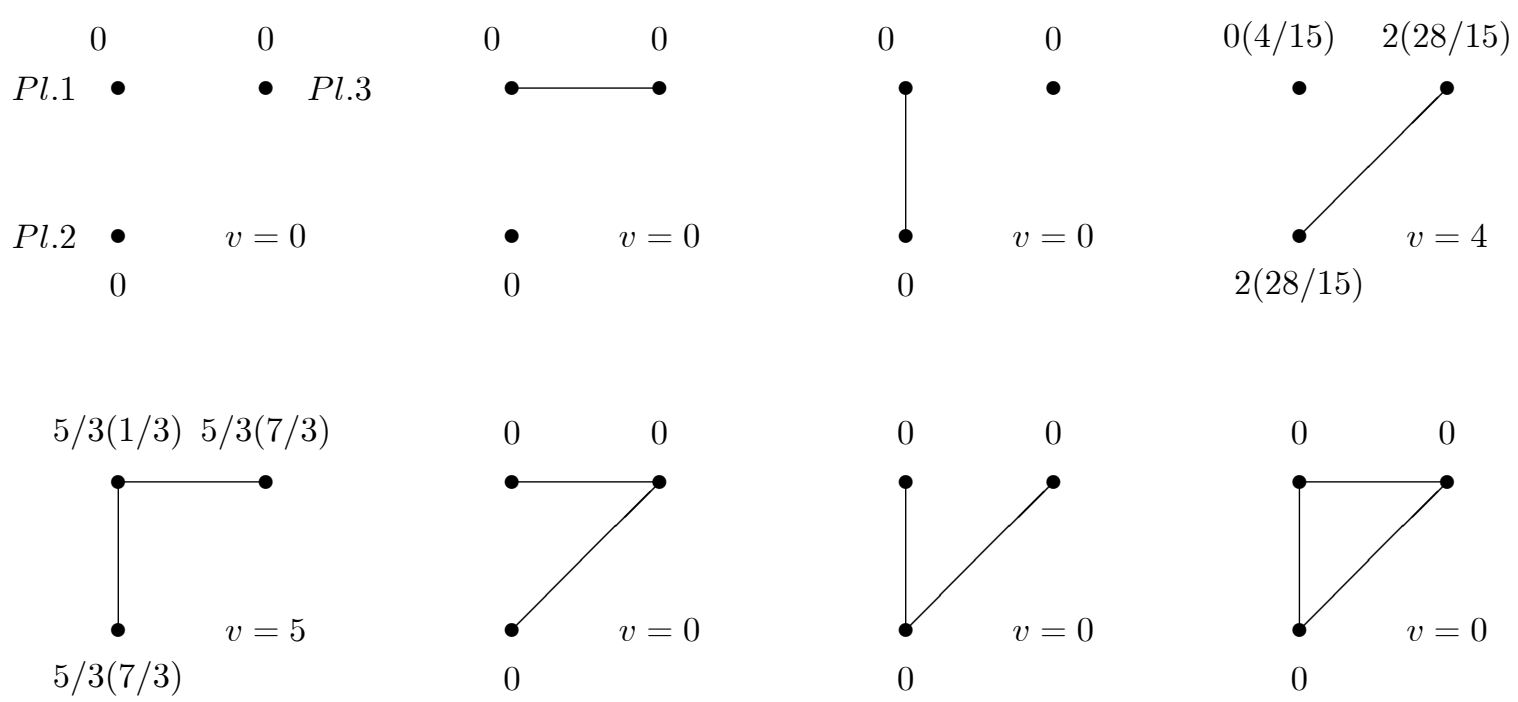

Figure 1: The Myerson value (The player-based flexible network allocation rule).

\section{Allocation rules with farsighted players}

The equal bargaining power property imposes that, for each link $i j$ in a network $g$, both players $i$ and $j$ should equally benefit or suffer when bargaining over how to allocate value taking as reference network the adjacent subnetwork $g-i j$. Hence, equal bargaining power presumes that players are myopic, not farsighted, in the sense that they do not forecast how others might react if they break the link $i j$. 
For instance, the severing of $i j$ might lead to subsequent severing or addition of another link. Once players are farsighted, equal bargaining power will impose that players equally benefit or suffer when bargaining over how to allocate value taking as reference network or bargaining threat, not necessarily adjacent subnetworks, but networks that may be reached from adjacent networks through a sequence of networks when players form or delete links based on the improvement the end network offers relative to the current one.

\section{Von Neumann-Morgenstern farsighted stability with bargaining}

We now propose the notion of von Neumann-Morgenstern farsighted stability with bargaining, to predict which networks are likely to emerge and which allocations are going to be agreed upon among farsighted players when allocations and links are determined jointly.

We first introduce the notion of farsighted improving path from Herings, Mauleon and Vannetelbosch (2009) and the notion of bargaining threat. A farsighted improving path is a sequence of networks that can emerge when players form or sever links based on the improvement the end network offers relative to the current network. Each network in the sequence differs by one link from the previous one. If a link is added, then the two players involved must both prefer the end network to the current network, with at least one of the two strictly preferring the end network. If a link is deleted, then it must be that at least one of the two players involved in the link strictly prefers the end network. Formally, a farsighted improving path from a network $g$ to a network $g^{\prime} \neq g$ is a finite sequence of graphs $g_{1}, \ldots, g_{K}$ with $g_{1}=g$ and $g_{K}=g^{\prime}$ such that for any $k \in\{1, \ldots, K-1\}$ either: (i) $g_{k+1}=g_{k}-i j$ for some $i j$ such that $y_{i}\left(g_{K}, v\right)>y_{i}\left(g_{k}, v\right)$ or $y_{j}\left(g_{K}, v\right)>y_{j}\left(g_{k}, v\right)$, or (ii) $g_{k+1}=g_{k}+i j$ for some ij such that $y_{i}\left(g_{K}, v\right)>y_{i}\left(g_{k}, v\right)$ and $y_{j}\left(g_{K}, v\right) \geq y_{j}\left(g_{k}, v\right)$. For a given network $g$, let $F(g)$ be the set of networks that can be reached by a farsighted improving path from $g$. Notice that $F(g)$ may contain many networks and that a network $g^{\prime} \in F(g)$ might be the endpoint of several farsighted improving paths starting in $g$.

A bargaining threat $z$ is a function that assigns to each network $g \in \mathbb{G}$ a network $z_{i}(g) \in \mathbb{G}$ for each player $i \in N$. Intuitively, when player $i$ is negotiating how to share the surplus with other players she is linked to in $g$, she has in mind the payoff she might obtain at some other network, $z_{i}(g)$, not necessarily adjacent to $g$ since 
players are farsighted.

A set of networks is a von Neumann-Morgenstern farsightedly stable set with bargaining if there exists an allocation rule and a bargaining threat such that the following conditions hold. First, there is no farsighted improving path from one network inside the set to another network inside the set (internal stability). Second, from any network outside the set there is a farsighted improving path to some network inside the set (external stability). Third, the value of each network is allocated among players so that players suffer or benefit equally from being linked to each other compared to the allocation they would obtain at their respective bargaining threat (equal bargaining power). Fourth, the bargaining threat at each network is credible. Credibility means that the threat can be reached by a farsighted improving path emanating from some network adjacent to the network over which bargaining takes place. Formally, von Neumann-Morgenstern farsightedly stable sets with bargaining are defined as follows.

Definition 1. A set of networks $G \subseteq \mathbb{G}$ is a von Neumann-Morgenstern farsightedly stable set with bargaining if there exists an allocation rule $y$ and a bargaining threat $z$ such that

(i) $\forall g \in G, F(g) \cap G=\emptyset$; (Internal Stability)

(ii) $\forall g^{\prime} \in \mathbb{G} \backslash G, F\left(g^{\prime}\right) \cap G \neq \emptyset$; (External Stability)

(iii) $\forall g \in \mathbb{G}$ and $i j \in g$,

(a) $y_{i}(g, v)-y_{i}\left(z_{i}(g), v\right)=y_{j}(g, v)-y_{j}\left(z_{j}(g), v\right)$, (Equal Bargaining Power)

(b) $z_{i}(g) \in\left(F\left(g^{\prime \prime}\right) \cup\left\{g^{\prime \prime}\right\}\right) \cap G \neq \emptyset$ for some $g^{\prime \prime} \in A_{i}(g)$ and $z_{j}(g) \in\left(F\left(g^{\prime \prime \prime}\right) \cup\right.$ $\left.\left\{g^{\prime \prime \prime}\right\}\right) \cap G \neq \emptyset$ for some $g^{\prime \prime \prime} \in A_{j}(g)$. (Consistency)

Condition (i) in Definition 1 is the internal stability condition. From any network within $G$, there is no farsighted improving path leading to some other network in $G$. Condition (ii) in Definition 1 requires external stability and implies that the networks within the set are robust to perturbations. From any network outside $G$, there is a farsighted improving path leading to some network in $G .{ }^{16}$ Condition (ii) implies that if a set of networks is a von Neumann-Morgenstern farsightedly stable

\footnotetext{
${ }^{16}$ There are some random dynamic models of network formation that are based on myopic incentives to form links such as Jackson and Watts (2002) and Tercieux and Vannetelbosch (2006). These models aim to use the random process to select from the set of pairwise stable networks.
} 
set with bargaining, it is non-empty. Part (a) of condition (iii) in Definition 1 is the equal bargaining power property for farsighted players. It requires that for each pair of players linked in $g$ both players suffer or benefit equally from being linked with respect to their respective bargaining threat. Part (b) of condition (iii) in Definition 1 imposes a consistency requirement on the bargaining threat. When bargaining how to share the value at $g$, the bargaining threat $z_{i}(g)$ for each player $i$ has to be such that the threat can be reached by a farsighted improving path emanating from some adjacent network to $g$ when the adjacent network is not in $G$. That is, $z_{i}(g) \in F\left(g^{\prime \prime}\right)$ for some $g^{\prime \prime} \in A_{i}(g)$ when $g^{\prime \prime} \notin G$. Moreover, $z_{i}(g)$ belongs to $G$, which makes $z_{i}(g)$ a credible threat. ${ }^{17}$

Example 1 (continued). We observe that $E(v)=\{\{12,13\}\}$ is not a von NeumannMorgenstern farsightedly stable set with bargaining if $y$ is the Myerson value allocation rule since external stability is violated. There is no farsighted improving path from the network $\{23\}$ to the network $\{12,13\}$ if $y$ is the Myerson value; players 2 and 3 obtain a higher payoff in $\{23\}$ than in $\{12,13\}$. Notice that the set $\{\{23\}\}$ is not a von Neumann-Morgenstern farsightedly stable set with bargaining if $y$ is the Myerson value because it violates equal bargaining power for farsighted players at networks where some players are linked to each other and $v=0$. For instance, players 1 and 2 obtain both 0 at $\{12\}$ but obtain, respectively, 0 and 2 at their consistent bargaining threat $\left(z_{i}(\{12\})=\{23\}\right)$.

If $y$ is the player-based flexible network allocation rule, then $E(v)=\{\{12,13\}\}$ is a not a von Neumann-Morgenstern farsightedly stable set with bargaining even though internal stability, external stability and consistency in Definition 1 are satisfied. But, equal bargaining power for farsighted players is violated at networks where some players are linked to each other and $v=0$. In general, equal bargaining power for farsighted players may be violated at any network. For instance, take $v^{\prime}$ such $v^{\prime}(g)=v(g)$ for all $g$ except for $\{12\}$ where $v^{\prime}(\{12\},\{12\})=2$ and $v^{\prime}(\{3\},\{12\})=0$. The player-based flexible networks allocations for the different network configurations are given in Figure 2. We observe that $E(v)=\{\{12,13\}\}$ satisfies internal stability, external stability and consistency, but equal bargaining power is now violated at all networks $g \neq\{12,13\}$ included networks $\{12\}$ and $\{23\}$.

However, $E(v)=\{\{12,13\}\}$ is a von Neumann-Morgenstern farsightedly stable set with bargaining if $y$ is the allocation rule given in Table 1 with $1 / 2>\varepsilon>0$.

\footnotetext{
${ }^{17}$ Notice that we do not impose that each player chooses her best alternative among her credible threats.
} 
$\{13,23\},\{12,23\}$

\begin{tabular}{ccccccc} 
& $\emptyset$ & $\{12\}$ & $\{13\}$ & $\{23\}$ & $\{12,13\}$ & $\{12,13,23\}$ \\
\hline$y_{1}$ & 0 & $-(1+3 \varepsilon) / 2$ & $-(1+3 \varepsilon) / 2$ & 0 & $1-2 \varepsilon$ & $-(2+6 \varepsilon) / 3$ \\
$y_{2}$ & 0 & $(1+3 \varepsilon) / 2$ & 0 & 2 & $2+\varepsilon$ & $(1+3 \varepsilon) / 3$ \\
$y_{3}$ & 0 & 0 & $(1+3 \varepsilon) / 2$ & 2 & $2+\varepsilon$ & $(1+3 \varepsilon) / 3$
\end{tabular}

Table 1: A farsighted allocation rule for value function $v$

It can be easily verified that internal stability and external stability are satisfied for $1 / 2>\varepsilon>0$, and that this allocation rule satisfies equal bargaining power for farsighted players and consistency at all networks. This allocation rule also satisfies component balance, a property that is not required by the concept of von NeumannMorgenstern farsighted stability with bargaining. Component balance makes sense when the value function is component additive, and the value function of our example satisfies component additivity. Notice that the allocation rule given in Table 1 is not the unique one that may arise with $E(v)=\{\{12,13\}\}$ when players are farsighted.

$\{13,23\},\{12,23\}$

\begin{tabular}{ccccccc} 
& $\emptyset$ & $\{12\}$ & $\{13\}$ & $\{23\}$ & $\{12,13\}$ & $\{12,13,23\}$ \\
\hline$y_{1}$ & 0 & $-(1+4 \varepsilon) / 2$ & $-(1+5 \varepsilon) / 2$ & 0 & $1-2 \varepsilon$ & $-(2+9 \varepsilon) / 3$ \\
$y_{2}$ & 0 & $(1+4 \varepsilon) / 2$ & 0 & $(4-\varepsilon) / 2$ & $2+\varepsilon$ & $(1+3 \varepsilon) / 3$ \\
$y_{3}$ & 0 & 0 & $(1+5 \varepsilon) / 2$ & $(4+\varepsilon) / 2$ & $2+2 \varepsilon$ & $(1+6 \varepsilon) / 3$
\end{tabular}

Table 2: Another farsighted allocation rule for value function $v$

For instance, the set $E(v)=\{\{12,13\}\}$ is also a von Neumann-Morgenstern farsightedly stable set with bargaining if $y$ is the allocation rule given in Table 2 with $1 / 3>\varepsilon>0$. This allocation rule leads to a division of the value of the efficient network $\{12,23\}$ where player 3 obtains a larger share than player 2 even though players 2 and 3 are symmetric in $\{12,23\}$.

Proposition 1. Take any bargaining threat $z$. If y satisfies component efficiency and equal bargaining power for farsighted players then $y$ is such that

$$
y_{i}(g, v)=y_{i}\left(z_{i}(g), v\right)+\frac{1}{\# S}\left[v(S, g)-\sum_{j \in S} y_{j}\left(z_{j}(g), v\right)\right] \quad \forall i \in S, S \in \Pi(g) .
$$

Proof. See the appendix. 


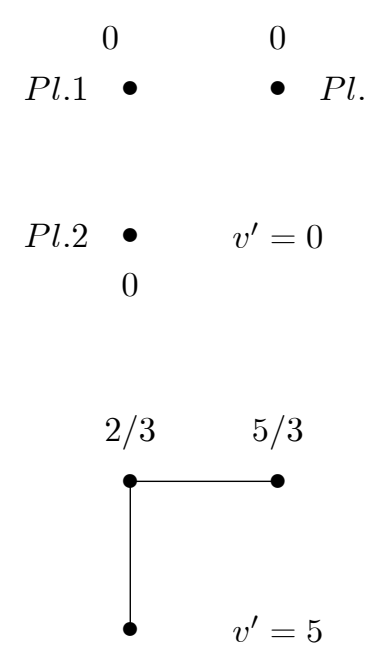

$8 / 3$

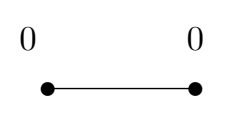

- $\quad v^{\prime}=0$

0

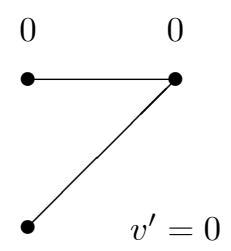

0

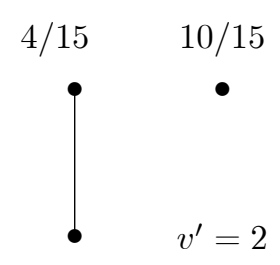

$16 / 15$

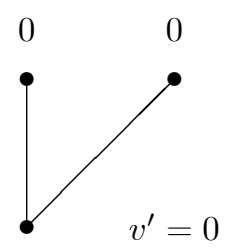

0

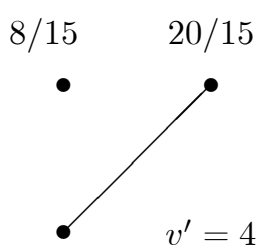

$32 / 15$

Figure 2: The player-based flexible network allocation rule.

Proposition 1 tells us that, if the allocation rule satisfies component efficiency and equal bargaining power for farsighted players then this allocation rule will lead to a division of the value of the component where each player gets the payoff at her bargaining threat plus an equal share of the excess between the value and the sum of the threats.

We now turn to the existence of a von Neumann-Morgenstern farsightedly stable set with bargaining. Is the set of strongly efficient networks $E(v)$ always a von Neumann-Morgenstern farsightedly stable set with bargaining?

Proposition 2. The set of strongly efficient networks $E(v)$ is a von NeumannMorgenstern farsightedly stable set with bargaining if $y$ is the egalitarian allocation rule.

Proof. [Internal stability] We have that $y_{i}(g, v)=y_{j}(g, v)=y_{i}\left(g^{\prime}, v\right)=y_{j}\left(g^{\prime}, v\right)$ for all $i, j \in N$, for all $g, g^{\prime} \in E(v)$ since $y$ is the egalitarian allocation rule. Hence, there is no farsighted improving path from any $g \in E(v)$ to another $g^{\prime} \in E(v)$, and $E(v)$ satisfies internal stability. [External stability] In addition, $y_{i}(g, v)>y_{i}\left(g^{\prime}, v\right)$ for all $i \in N$, for all $g \in E(v)$ and $g^{\prime} \notin E(v)$ since $y$ is the egalitarian allocation rule and $g$ is efficient. Hence, there is a farsighted improving from any $g^{\prime} \notin E(v)$ to some $g \in E(v)$, and $E(v)$ satisfies external stability. [Equal bargaining power] Since $y_{i}(g, v)=y_{j}(g, v)=y_{i}\left(g^{\prime}, v\right)=y_{j}\left(g^{\prime}, v\right)$ for all $i, j \in N$, for all $g, g^{\prime} \in E(v)$, and $y_{i}\left(g^{\prime \prime}, v\right)=y_{j}\left(g^{\prime \prime}, v\right)$ for all $i, j \in N$, for all $g^{\prime \prime} \notin E(v)$, we have that equal 
bargaining power for farsighted players is satisfied for any $z$ such that $z_{i}(g) \in E(v)$ for $g \in \mathbb{G}$. [Consistency] Since there is a farsighted improving from any $g^{\prime} \notin E(v)$ to some $g \in E(v)$, there exists some $z$ such that for all $g \in \mathbb{G}$ and $i j \in g$ we have that $z_{i}(g) \in\left(F\left(g^{\prime \prime}\right) \cup\left\{g^{\prime \prime}\right\}\right) \cap E(v) \neq \emptyset$ for some $g^{\prime \prime} \in A_{i}(g)$ and $z_{j}(g) \in$ $\left(F\left(g^{\prime \prime \prime}\right) \cup\left\{g^{\prime \prime \prime}\right\}\right) \cap E(v) \neq \emptyset$ for some $g^{\prime \prime \prime} \in A_{j}(g)$.

Proposition 2 shows that the egalitarian allocation rule guarantees the existence of a von Neumann-Morgenstern farsightedly stable set with bargaining. However, this allocation rule violates component efficiency and each player's allocation is independent of her position in the network.

Lemma 1. Consider any anonymous, component additive and top convex value function $v$. The set of strongly efficient networks $E(v)$ is the unique von NeumannMorgenstern farsightedly stable set with bargaining if $y$ is the componentwise egalitarian allocation rule.

Proof. Take any anonymous and component additive value function $v$. Top convexity implies that all components of a strongly efficient network must lead to the same per-capita value (if some component led to a lower per capita value than the average, then another component would have to lead to a higher per capita value than the average which would contradict top convexity). Top convexity also implies that, under the componentwise egalitarian allocation rule, any $g \in E(v)$ Pareto dominates all $g^{\prime} \notin E(v)$. Then, it is immediate that $F(g)=\emptyset$ for all $g \in E(v)$ [Internal stability] and that $F\left(g^{\prime}\right) \cap E(v) \neq \emptyset$ for all $g^{\prime} \in \mathbb{G} \backslash E(v)$ [External stability]. Since $v$ is top convex, all components of any network $g \in E(v)$ lead to the same per-capita value. Since $y$ is the componentwise egalitarian allocation rule, equal bargaining power for farsighted players is satisfied for any $z$ such that $z_{i}(g) \in E(v)$ for $g \in \mathbb{G}$ [Equal bargaining power]. Since $F\left(g^{\prime}\right) \cap E(v) \neq \emptyset$ for all $g^{\prime} \in \mathbb{G} \backslash E(v)$, there exists some $z$ such that for all $g \in \mathbb{G}$ and $i j \in g$ we have that $z_{i}(g) \in\left(F\left(g^{\prime \prime}\right) \cup\left\{g^{\prime \prime}\right\}\right) \cap E(v) \neq \emptyset$ for some $g^{\prime \prime} \in A_{i}(g)$ and $z_{j}(g) \in\left(F\left(g^{\prime \prime \prime}\right) \cup\left\{g^{\prime \prime \prime}\right\}\right) \cap E(v) \neq \emptyset$ for some $g^{\prime \prime \prime} \in A_{j}(g)$ [Consistency]. Thus, $E(v)$ satisfies internal stability, external stability, equal bargaining power and consistency. It is the unique von Neumann-Morgenstern farsightedly stable set with bargaining if $y$ is the componentwise egalitarian allocation rule because $F(g)=\emptyset$ for all $g \in E(v)$ (hence, external stability would be violated if not all $g \in E(v)$ belong to $G$ ) and $F\left(g^{\prime}\right) \cap E(v) \neq \emptyset$ for all $g^{\prime} \in \mathbb{G} \backslash E(v)$ (hence, internal stability would be violated if some $g^{\prime} \notin E(v)$ belong to $G$ ). 

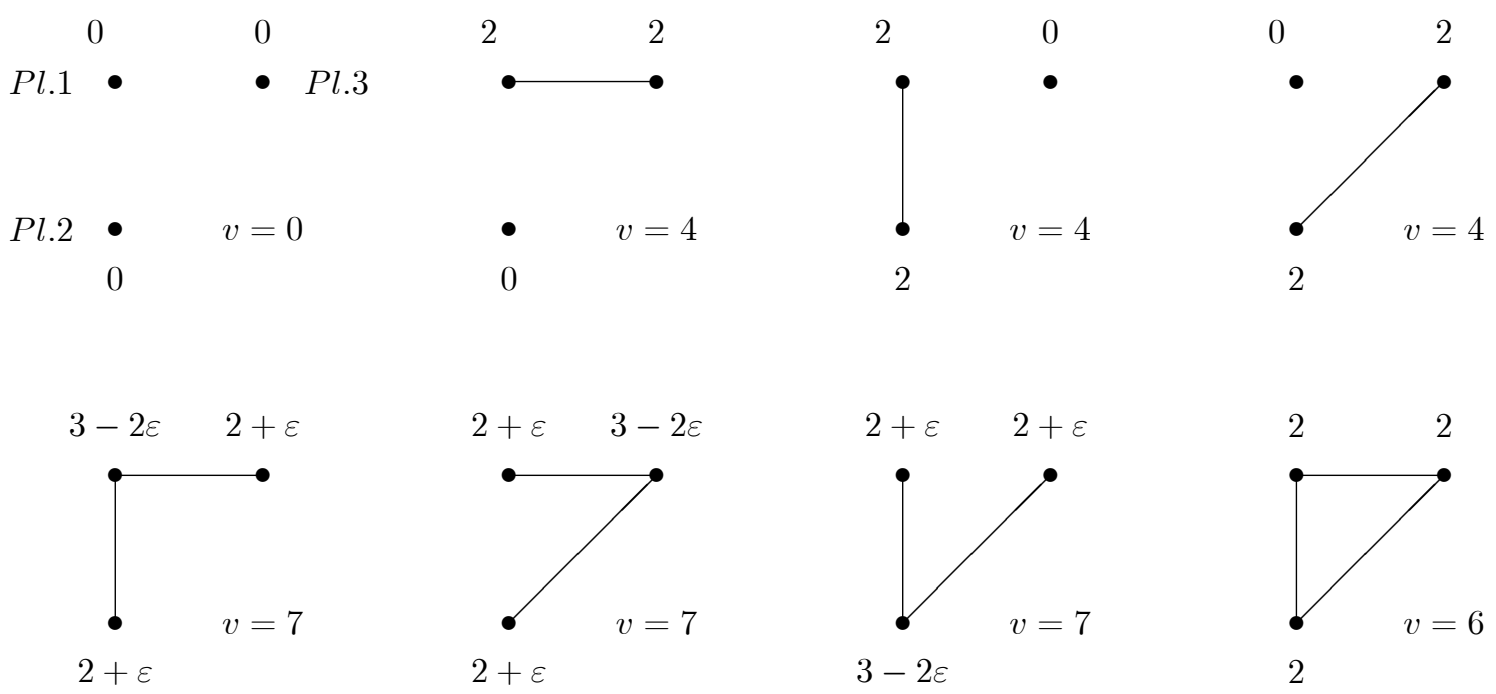

$3-2 \varepsilon$

2

Figure 3: Top convexity and farsighted stability with bargaining.

Proposition 3. Consider any anonymous, component additive and top convex value function $v$. If $y$ is component efficient and anonymous then $E(v)$ is a von NeumannMorgenstern farsightedly stable set with bargaining if and only if $y$ is the componentwise egalitarian allocation rule.

Proof. Take any anonymous, component additive and top convex value function $v$. Suppose $y$ is component efficient and anonymous. We will show that $E(v)$ is a von Neumann-Morgenstern farsightedly stable set with bargaining if and only if $y$ is the componentwise egalitarian allocation rule.

\section{$(\Rightarrow)$}

(1) Suppose $E(v)$ is a von Neumann-Morgenstern farsightedly stable set with bargaining and is a singleton set. Then ,either it consists of the complete network or the empty network because $v$ is anonymous. Since $y$ is anonymous, we have equal sharing of the value of the efficient network $g \in E(v)$. Component efficiency, equal bargaining power and consistency imply that there is equal sharing of the value of each component among the members of the component for each $g^{\prime} \notin E(v) .{ }^{18}$ Hence, $y$ is the componentwise egalitarian allocation rule.

(2) Suppose $E(v)$ is a von Neumann-Morgenstern farsightedly stable set with bargaining but is not a singleton set. Top convexity implies that all components

\footnotetext{
${ }^{18}$ Equal bargaining power and consistency imply that the allocation rule is either the componentwise egalitarian allocation rule or the egalitarian allocation rule. But, the egalitarian allocation rule violates component efficiency.
} 
of any $g \in E(v)$ have the same per-capita value, and that all components of any $g^{\prime}$ such that $g^{\prime} \notin E(v)$ have a lower per-capita value than the per-capita value of any component of any $g \in E(v)$. Internal stability for $E(v)$ implies that players share equally the value of any $g \in E(v)$. Otherwise, since $y$ is component efficient and anonymous and $v$ is top convex, there would exist some farsighted improving path from some $g \in E(v)$ to another $g^{\prime \prime} \in E(v)$. Component efficiency, equal bargaining power and consistency imply that there is equal sharing of the value of each component among the members of the component for each $g^{\prime} \notin E(v)$. Hence, $y$ is the componentwise egalitarian allocation rule.

$(\Leftarrow)$ From Lemma 1 .

Example 2 Top convexity and farsighted stability with bargaining. Take $N=$ $\{1,2,3\}$ and the anonymous, component additive, and top convex value function defined by $v(\{12,13,23\})=6, v(\{12,13\})=v(\{12,23\})=v(\{13,23\})=7, v(\{12\})=$ $v(\{13\})=v(\{23\})=4$, and $v(\emptyset)=0$. We have depicted in Figure 3 the network configurations with their associated allocations.

First, we show that if $y$ is the componentwise egalitarian allocation rule (i.e. $\varepsilon=$ $1 / 3)$ then $E(v)$ is the unique von Neumann-Morgenstern farsightedly stable set with bargaining. We have $F(\emptyset)=\mathbb{G} \backslash\{\emptyset,\{12,13,23\}\} ; F(\{13\})=F(\{12\})=F(\{23\})=$ $F(\{12,13,23\})=\{\{12,13\},\{12,23\},\{13,23\}\} ;$ and $F(\{12,13\})=F(\{12,23\})=$ $F(\{13,23\})=\emptyset$. Then, $E(v)$ satisfies internal stability and external stability. The componentwise egalitarian allocation rule also satisfies equal bargaining power and consistency since there is a $z$ such that $z_{i}(g) \in E(v)$ for $g \in \mathbb{G}$ and $F(g) \cap E(v) \neq \emptyset$ for all $g \notin E(v)$. Hence, $E(v)$ is a von Neumann-Morgenstern farsightedly stable set with bargaining. We now show that $E(v)$ is the unique von NeumannMorgenstern farsightedly stable set with bargaining. Suppose that $G$ is a von Neumann-Morgenstern farsightedly stable set with bargaining. We have that $E(v) \subseteq$ $G$ since $F(g)=\emptyset$ for all $g \in E(v)$; otherwise, $G$ would violate external stability. In addition, if $E(v) \varsubsetneqq G$ then internal stability is violated because $F(g) \cap E(v) \neq \emptyset$ for all $g \notin E(v)$. Thus, $E(v)=G$.

Second, is $E(v)$ a von Neumann-Morgenstern farsightedly stable set with bargaining if the anonymous and component efficient allocation rule is such that $\varepsilon \neq 1 / 3$ $(0<\varepsilon<1 / 3)$ ? Then, equal bargaining power and consistency can still be satisfied as well as external stability but internal stability is violated since now $g \in F\left(g^{\prime}\right)$, for any $g, g^{\prime} \in E(v)\left(g \neq g^{\prime}\right)$. Hence, once the allocation rule is determined jointly with the farsighted stability of the network and the value function is anonymous, 
component additive and top convex, the set of strongly efficient networks is a von Neumann-Morgenstern farsightedly stable set with bargaining only if the sharing of the value follows the componentwise egalitarian allocation rule.

The next question is whether some $G \neq E(v)$ can be a von Neumann-Morgenstern farsightedly stable set with bargaining if $y$ is anonymous and the value function is anonymous, component additive and top convex.

Example 2 (continued). If $y$ is anonymous then candidate allocations to support a von Neumann-Morgenstern farsightedly stable set with bargaining are given in Figure 3. For $\varepsilon<0$, then $\{\{12,13,23\}\}$ is the unique set to satisfy internal stability and external stability. But, the allocations for $\{i j, i k\}$ violate equal bargaining power because of the consistency requirement. For $\varepsilon=0$, then $\{\{i j, i k\},\{12,13,23\}\}$ are the sets to satisfy internal stability and external stability. But, the allocations for $\{i j, j k\}$ and $\{i k, j k\}$ violate equal bargaining power because of the consistency requirement. For $0<\varepsilon<1 / 3$ and $1 / 3<\varepsilon \leq 1 / 2$, then $\{\{i j, i k\}\}$ are the sets to satisfy internal stability and external stability. But, the allocations for $\{i j\}$, $\{i k\},\{i j, j k\},\{i k, j k\},\{12,13,23\}$ violate equal bargaining power because of the consistency requirement. For $1 / 2<\varepsilon$, then $\{\{i j\},\{12,13,23\}\}$ are the sets to satisfy internal stability and external stability. But, the allocations for $\{i j, j k\},\{i j, i k\}$ violate equal bargaining power because of the consistency requirement. For $1 / 3=$ $\varepsilon$, the allocation rule reverts to the componentwise egalitarian allocation rule and $E(v)=\{\{12,13\},\{12,23\},\{13,23\}\}$ is a von Neumann-Morgenstern farsightedly stable set with bargaining. Hence, $E(v)$ is the unique von Neumann-Morgenstern farsightedly stable set with bargaining and the componentwise egalitarian allocation rule emerges endogenously.

Proposition 4. Consider any anonymous, component additive and top convex value function $v$. If $y$ is component efficient and anonymous then $E(v)$ is the unique von Neumann-Morgenstern farsightedly stable set with bargaining.

Proof. See the appendix.

\section{Pairwise farsighted stability with bargaining}

We now incorporate the property of equal bargaining power for farsighted players into the original definition of a pairwise farsightedly stable set due to Herings, 
Mauleon and Vannetelbosch (2009). Formally, pairwise farsighted stability with bargaining is defined as follows.

Definition 2. A set of networks $G \subseteq \mathbb{G}$ is pairwise farsightedly stable with bargaining if there exists an allocation rule $y$ and a bargaining threat $z$ such that

(i) $\forall g \in G$,

(a) $\forall i j \notin g$ such that $g+i j \notin G, \exists g^{\prime} \in F(g+i j) \cap G$ such that $\left(y_{i}\left(g^{\prime}, v\right), y_{j}\left(g^{\prime}\right.\right.$, $v))=\left(y_{i}(g, v), y_{j}(g, v)\right)$ or $y_{i}\left(g^{\prime}, v\right)<y_{i}(g, v)$ or $y_{j}\left(g^{\prime}, v\right)<y_{j}(g, v)$,

(b) $\forall i j \in g$ such that $g-i j \notin G, \exists g^{\prime}, g^{\prime \prime} \in F(g-i j) \cap G$ such that $y_{i}\left(g^{\prime}, v\right) \leq$ $y_{i}(g, v)$ and $y_{j}\left(g^{\prime \prime}, v\right) \leq y_{j}(g, v)$,

(ii) $\forall g^{\prime} \in \mathbb{G} \backslash G, F\left(g^{\prime}\right) \cap G \neq \emptyset$.

(iii) $\forall g \in \mathbb{G}$ and $i j \in g$,

(a) $y_{i}(g, v)-y_{i}\left(z_{i}(g), v\right)=y_{j}(g, v)-y_{j}\left(z_{j}(g), v\right)$,

(b) $z_{i}(g) \in\left(F\left(g^{\prime \prime}\right) \cup\left\{g^{\prime \prime}\right\}\right) \cap G \neq \emptyset$ for some $g^{\prime \prime} \in A_{i}(g)$ and $z_{j}(g) \in\left(F\left(g^{\prime \prime \prime}\right) \cup\right.$ $\left.\left\{g^{\prime \prime \prime}\right\}\right) \cap G \neq \emptyset$ for some $g^{\prime \prime \prime} \in A_{j}(g)$.

(iv) $\nexists G^{\prime} \varsubsetneqq G$ such that $G^{\prime}$ satisfies Conditions (i), (ii), and (iii).

Condition (ia) in Definition 2 captures that adding a link $i j$ to a network $g \in$ $G$ that leads to a network outside of $G$, is deterred by the threat of ending in $g^{\prime}$. Here $g^{\prime}$ is such that there is a farsightedly improving path from $g+i j$ to $g^{\prime}$. Moreover, $g^{\prime}$ belongs to $G$, which makes $g^{\prime}$ a credible threat. Condition (ib) is a similar requirement, but then for the case where a link is severed. Condition (ii) in Definition 2 requires external stability and implies that the networks within the set are robust to perturbations. From any network outside $G$ there is a farsightedly stable path leading to some network in $G$. Condition (iiia) in Definition 2 is the equal bargaining power property for farsighted players. Condition (iiib) in Definition 2 imposes a consistency requirement on the bargaining threat. Condition (iv) in Definition 2 is a minimality condition.

Proposition 5. If $G$ is a von Neumann-Morgenstern farsightedly stable set with bargaining, then $G$ is a pairwise farsightedly stable set with bargaining. 
Proof. Suppose $G$ is a von Neumann-Morgenstern farsightedly stable set with bargaining. Then, conditions (ii) and (iii) in Definition 2 are trivially satisfied for $G$.

Suppose Condition (i) in Definition 2 is not satisfied. Then there is $g \in G$ and a deviation to $g^{\prime} \notin G$ such that every $g^{\prime \prime} \in F\left(g^{\prime}\right) \cap G$ defeats $g .{ }^{19}$ In particular, it then follows that $g^{\prime \prime} \in F(g)$, a contradiction, since by condition (i) in Definition 1 there is no $g^{\prime \prime} \in G$ with that property. Consequently, Condition (i) in Definition 2 holds.

To verify condition (iv) in Definition 2, suppose there is a proper subset $G^{\prime} \varsubsetneqq G$ that satisfies conditions (i), (ii) and (iii). Let $g$ be in $G$ but not in $G^{\prime}$. Then, $F(g) \cap G^{\prime} \subseteq F(g) \cap G=\emptyset$ since $G$ satisfies condition (i) in Definition 1. It follows that $G^{\prime} \varsubsetneqq G$ violates condition (ii) in Definition 2, leading to a contradiction. We have shown that $G$ is minimal.

From Proposition 5 we have that, in Example 2, $E(v)$ is a pairwise farsightedly stable set with bargaining where the allocation rule is the componentwise egalitarian allocation rule. ${ }^{20}$ However, Proposition 3 does not hold for the pairwise farsighted stability with bargaining. The set of strongly efficient networks $E(v)$ is a pairwise farsightedly stable set with bargaining even for anonymous allocation rules where the value of each component is not shared equally among the members of the component.

Example 2 (continued). If $y$ is anonymous then candidate allocations to support a von Neumann-Morgenstern farsightedly stable set with bargaining are given in Figure 3.

For $0<\varepsilon \leq 1 / 2$, the set $E(v)=\{\{12,13\},\{12,23\},\{13,23\}\}$ is a pairwise farsightedly stable set with bargaining. External stability is satisfied. Notice that pairwise farsighted stability with bargaining does not require internal stability. Equal bargaining power for farsighted players and consistency are satisfied. For instance, in $\{12\}$ the bargaining threat $z_{1}(\{12\})$ and $z_{2}(\{12\})$ can be respectively $\{12,13\}$ and $\{12,23\}$ (or simply $\{13,23\}$ for both players). Equal bargaining power is satisfied since $y_{1}(\{12\}, v)-y_{1}(\{12,13\}, v)=2-3+2 \varepsilon=y_{2}(\{12\}, v)-y_{2}(\{12,23\}, v)$ (or $\left.y_{1}(\{12\}, v)-y_{1}(\{13,23\}, v)=2-2-\varepsilon=y_{2}(\{12\}, v)-y_{2}(\{13,23\}, v)\right)$ and consistency is satisfied since $z_{1}(\{12\}), z_{2}(\{12\}) \in E(v)$ and $z_{1}(\{12\}), z_{2}(\{12\}) \in F(\emptyset)$.

\footnotetext{
${ }^{19} \mathrm{~A}$ network $g^{\prime}$ defeats $g$ if either $g^{\prime}=g-i j$ and $y_{i}\left(g^{\prime}, v\right)>y_{i}(g, v)$ or $y_{j}\left(g^{\prime}, v\right)>y_{j}(g, v)$, or if $g^{\prime}=g+i j$ with $y_{i}\left(g^{\prime}, v\right) \geq y_{i}(g, v)$ and $y_{j}\left(g^{\prime}, v\right) \geq y_{j}(g, v)$ with at least one inequality holding strictly.

${ }^{20}$ Grandjean, Mauleon and Vannetelbosch (2011) have shown that, if the allocation rule is exogenously given and is the componentwise egalitarian allocation rule, then the set of strongly efficient networks is the unique pairwise farsightedly stable set if and only if the value function is top convex.
} 
$E(v)$ is minimal. Any subset of $E(v)$ would violate equal bargaining power for $\varepsilon \neq 1 / 3$. Take $\{\{12,13\},\{12,23\}\} \subset E(v)$. Then, equal bargaining power is violated at $\{13,23\}$ because player 3 obtains an allocation smaller or equal than the allocations of players 1 and 2 at $\{12,13\}$ and $\{12,23\}$.

However, if all strongly efficient networks are componentwise symmetric, then Proposition 3 holds for the pairwise farsighted stability with bargaining. A network $g$ is said to be componentwise symmetric if every player belonging to the same component has the same number of links. Formally, $g$ is componentwise symmetric if for each $h \in C(g)$ we have that $\# N_{i}(h)=\# N_{j}(h)$ for all $i, j \in N(h)$.

Proposition 6. Consider any anonymous, component additive and top convex value function $v$ such that $E(v)$ consists only of componentwise symmetric networks. If $y$ is component efficient and anonymous then $E(v)$ is a pairwise farsightedly stable set with bargaining if and only if $y$ is the componentwise egalitarian allocation rule.

Proof. See the appendix.

\section{Discussion}

\subsection{The role of top convexity}

We now look at an example where the value function does not satisfy top convexity. We observe that von Neumann-Morgenstern farsighted stability with bargaining is less likely to sustain efficient networks than pairwise farsighted stability with bargaining.

Example 3 Value function not top convex. Take $N=\{1,2,3\}$ and the anonymous, component additive, and not top convex value function defined by $v(\{12,13,23\})=$ $1, v(\{12,13\})=v(\{12,23\})=v(\{13,23\})=4 / 3, v(\{12\})=v(\{13\})=v(\{23\})=$ 1 , and $v(\emptyset)=0$. We have depicted in Figure 4 the network configurations with anonymous and component efficient allocation rules.

a) $0 \leq \varepsilon<1 / 36$. There is no von Neumann-Morgenstern farsightedly stable set with bargaining. The set $\{\{12\},\{13\},\{23\}\}$ is a candidate but it violates internal stability. In addition, each set $\{\{i j\}\}$ violates equal bargaining power for farsighted players at, for instance, networks $\{i k\},\{j k\}$ and $\{12,13,23\}$. But, $\{\{12\},\{13\},\{23\}\}$ is a pairwise farsightedly stable set with bargaining only if $\varepsilon=0$. It can be easily verified that all conditions are satisfied. It is minimal since any 


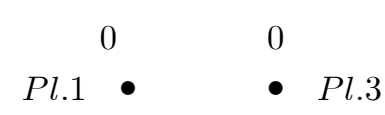

$P l .2 \bullet \quad v=0$

0

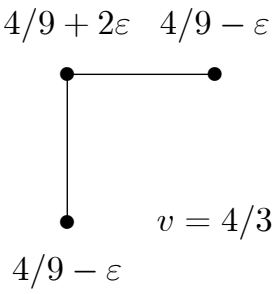

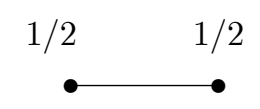

- $\quad v=1$

0

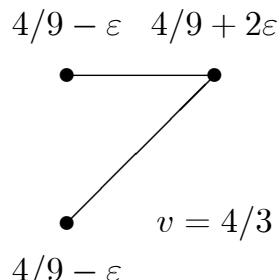

$4 / 9-\varepsilon$

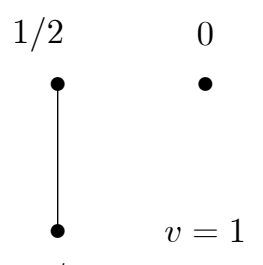

$1 / 2$

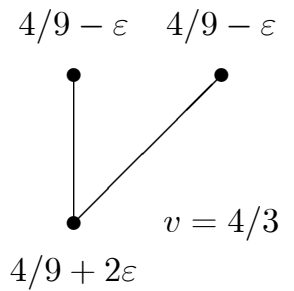

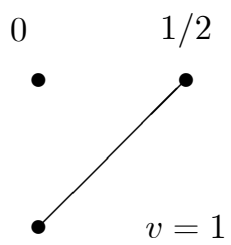

$1 / 2$

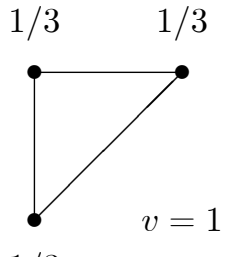

$1 / 3$

Figure 4: Value function not top convex and farsighted stability with bargaining.

nonempty subset $G \varsubsetneqq\{\{12\},\{13\},\{23\}\}$ would satisfy all conditions except that equal bargaining power would be violated at $g \in\{\{12\},\{13\},\{23\}\} \backslash G$.

b) $1 / 36 \leq \varepsilon<1 / 9$. The sets $\{\{12,13\},\{12,23\}\},\{\{12,13\},\{13,23\}\}$ and $\{\{12,23\},\{13,23\}\}$ are pairwise farsightedly stable sets with bargaining. External stability, equal bargaining power, consistency and minimality are satisfied. But, they are not von Neumann-Morgenstern farsightedly stable sets with bargaining because internal stability is violated.

c) $1 / 9 \leq \varepsilon<4 / 9$. There is a von Neumann-Morgenstern farsightedly stable set with bargaining only if $\varepsilon=1 / 6$. If $\varepsilon=1 / 6$, then $G^{\prime}=\{\{12\},\{13\},\{23\},\{12,13,23\}\}$ is a von Neumann-Morgenstern farsightedly stable set with bargaining. This set $G^{\prime}$ satisfies internal and external stability, equal bargaining power and consistency. Equal bargaining power requires that at $\{12,13\}$ we have $y_{1}(\{12\}, v)-y_{1}(\{12,13\}, v)=$ $y_{3}(\{12\}, v)-y_{3}(\{12,13\}, v)$. Since $y_{1}(\{12\}, v)-y_{1}(\{12,13\}, v)=1 / 2-4 / 9-2 \varepsilon$ and $y_{3}(\{12\}, v)-y_{3}(\{12,13\}, v)=0-4 / 9+\varepsilon$, equal bargaining power holds only if $\varepsilon=1 / 6$. Obviously, $G^{\prime}$ with $\varepsilon=1 / 6$ is also a pairwise farsightedly stable set with bargaining. However, $G^{\prime}$ is not the unique one. The set $E(v) \cup\{12,13,23\}$ is a pairwise farsightedly stable set with bargaining for $1 / 36 \leq \varepsilon<4 / 9$.

Hence, contrary to pairwise farsighted stability with bargaining, von NeumannMorgenstern farsighted stability with bargaining only leads to the emergence of inefficient networks. 


\subsection{The role of equal bargaining power}

We now reconsider Example 2 to show that if the allocation rule $y$ does not satisfy anonymity and/or equal bargaining power, then the componentwise egalitarian allocation does not emerge in the long run. Given a vector $w=\left(w_{1}, \ldots, w_{n}\right) \gg 0$, an allocation rule $y$ satisfies $w$-weighted bargaining power $^{21}$ for farsighted players if for all $v \in \mathcal{V}$, for all $g \in \mathbb{G}$, for all $i j \in g$,

$$
\frac{1}{w_{i}}\left[y_{i}(g, v)-y_{i}\left(z_{i}(g), v\right)\right]=\frac{1}{w_{j}}\left[y_{j}(g, v)-y_{j}\left(z_{j}(g), v\right)\right] .
$$

Consider the definition of von Neumann-Morgenstern farsighted stability with bargaining where the equal bargaining power condition (iiia) is replaced by the $w$ weighted bargaining power condition (iiia'). Suppose that $\left(w_{1}, w_{2}, w_{3}\right)$ is such that $1=w_{2}=w_{3} \leq w_{1}=\gamma$. For $\gamma>1$ the set $E(v)$ is still a von Neumann-Morgenstern farsightedly stable set with bargaining where players share equally the value for each network $g \in E(v)$ while they share unequally the value for each nonempty network $g \notin E(v)$ (the allocations for $\gamma=2$ are given in Table 3 ). Since each player obtains the same allocation in each efficient star network, the property of weighted bargaining power forces the players to agree on asymmetric allocations at symmetric networks. It can be easily verified that internal stability, external stability and consistency are satisfied too.

\begin{tabular}{ccccccccc} 
& $\emptyset$ & $\{12\}$ & $\{13\}$ & $\{23\}$ & $\{12,13\}$ & $\{12,23\}$ & $\{13,23\}$ & $\{12,13,23\}$ \\
\hline$y_{1}$ & 0 & $17 / 9$ & $17 / 9$ & 0 & $7 / 3$ & $7 / 3$ & $7 / 3$ & $22 / 12$ \\
$y_{2}$ & 0 & $19 / 9$ & 0 & 2 & $7 / 3$ & $7 / 3$ & $7 / 3$ & $25 / 12$ \\
$y_{3}$ & 0 & 0 & $19 / 9$ & 2 & $7 / 3$ & $7 / 3$ & $7 / 3$ & $25 / 12$
\end{tabular}

Table 3: Allocations satisfying $w$-weighted bargaining power for $\gamma=2$

Hence, the property of equal bargaining power for farsighted players is a tight condition for having the componentwise egalitarian allocation rule arising endogenously.

\subsection{The role of divergent bargaining threats}

The definitions of von Neumann-Morgenstern and pairwise farsighted stability with bargaining require that bargaining threats are credible but allow players to hold divergent credible bargaining threats. That is, two players who are bargaining over

\footnotetext{
${ }^{21}$ Such an allocation rule is called $w$-fairness in Dutta and Mutuswami (1997).
} 
how to share the benefits of being linked may disagree about the network that would be formed in case they do not reach an agreement.

We now reconsider Example 3 to illustrate the role of allowing players to hold divergent credible threats. Let $\varepsilon=1 / 36$. Then $\{\{12,13\},\{12,23\}\}$ is a pairwise farsightedly stable set with bargaining. Suppose now that players hold common bargaining threats if possible. Hence, when the players bargain at the complete network $\{12,13,23\}$ they hold either $\{12,13\}$ or $\{12,23\}$ as common credible threat. Take $\{12,13\}$ as common credible threat at $\{12,13,23\}$. If $v$ and $y$ are anonymous, then $\varepsilon$ cannot be equal to $1 / 36$; otherwise, players would have to share unequally the value at the complete network.

Thus, it seems reasonable to conjecture that requiring common bargaining threats if possible would make more likely the emergence of allocation rules that are not anonymous. For instance, $\{\{12,13\},\{12,23\}\}$ is not a pairwise farsightedly stable set when the allocations are those given in Figure 4 for $\varepsilon=1 / 36$, but it is a pairwise farsightedly stable set with bargaining for the allocations given in Table 4 .

$\{12,13\}$

\begin{tabular}{cccccccc} 
& $\emptyset$ & $\{12\}$ & $\{13\}$ & $\{23\}$ & $\{13,23\}$ & $\{12,23\}$ & $\{12,13,23\}$ \\
\hline$y_{1}$ & 0 & $13 / 24$ & $13 / 24$ & 0 & $15 / 36$ & $18 / 36$ & $14 / 36$ \\
$y_{2}$ & 0 & $11 / 24$ & 0 & $11 / 24$ & $15 / 36$ & $15 / 36$ & $11 / 36$ \\
$y_{3}$ & 0 & 0 & $11 / 24$ & $13 / 24$ & $18 / 36$ & $15 / 36$ & $11 / 36$
\end{tabular}

Table 4: A non-anonymous farsighted allocation rule for Example 3

\subsection{The role of component additivity}

Component additivity (or no externalities across components) means that the value of a component of the network does not depend on the structure of the network outside the component. We now look at situations where externalities across components can arise and we provide an alternative condition to top convexity such that the set of efficient networks remains the unique von Neumann-Morgenstern farsightedly stable set with bargaining. A value function $v$ is link monotonic (Navarro, 2013 b) if for any $S \in \Pi(g)$ and any $\left.i j \in g\right|_{S}$ we have

(i) $v(S, g)>v\left(S^{\prime}, g-i j\right)+v\left(S^{\prime \prime}, g-i j\right)$ if $S^{\prime} \in \Pi(g-i j)$ with $i \in S^{\prime}, S^{\prime \prime} \in \Pi(g-i j)$ with $j \in S^{\prime \prime}$, and $S^{\prime} \cap S^{\prime \prime}=\emptyset$;

(ii) $v(S, g)>v(S, g-i j)$ if $S \in \Pi(g-i j)$. 
A value function $v$ satisfies strong critical-link monotonicity (Navarro, 2013b) if $v$ is link monotonic and if for any $g$, any $S \in \Pi(g)$ and any $\left.i j \in g\right|_{S}$ such that $\# \Pi(g)=$ $\# \Pi(g-i j)-1$ we have $v(S, g) / \# S>\max \left\{v\left(S^{\prime}, g-i j\right) / \# S^{\prime}, v\left(S^{\prime \prime}, g-i j\right) / \# S^{\prime \prime}\right\}$ where $S^{\prime} \in \Pi(g-i j)$ with $i \in S^{\prime}$ and $S^{\prime \prime} \in \Pi(g-i j)$ with $j \in S^{\prime \prime}$. The link $i j$ is said to be critical. That is, if it is severed, then the component that it was a part of will become two components (or one of the nodes will become disconnected). Strong critical-link monotonicity imposes that if we add a link to the network such that two components become connected then the per-capita value of the new component is greater than the per-capita value of any of the two component before adding the link.

Proposition 7. Consider any value function that satisfies anonymity and strong critical-link monotonicity. Suppose that $y$ is component efficient and anonymous. The set $\left\{g^{N}\right\}$ is the unique von Neumann-Morgenstern farsightedly stable set with bargaining if and only if $y$ is the componentwise egalitarian allocation rule.

Proof. See the appendix.

Thus, if the value function satisfies anonymity and strong critical-link monotonicity and the allocation rule satisfies component efficient and anonymous, then the strongly efficient network is likely to emerge in the long run together with the componentwise egalitarian allocation rule when players are farsighted. In addition, Navarro (2013b) has shown that there exists a forward-looking network formation process consisting of an allocation rule and a transition probability matrix such that the allocation rule is component efficient and the complete network is the only absorbing state of the transition probability matrix for any strictly positive common discount factor.

\section{Conclusion}

We have studied the stability of social and economic networks when farsighted players simultaneously form links and bargain over allocations. In particular, we have shown that the set of strongly efficient networks is the unique von NeumannMorgenstern farsightedly stable set with bargaining if the allocation rule is anonymous and component efficient and the value function is top convex. In addition, the componentwise egalitarian allocation rule emerges endogenously. 


\section{Acknowledgments}

We thank Ana Mauleon for useful comments and suggestions as well as participants to the PET 13 Public Economic Theory Conference, the 5th UECE Lisbon Meeting in Game Theory and Applications, and the Bordeaux Economic Theory Workshop on Interactions, Institutions and Design. Vincent Vannetelbosch is Senior Research Associate of the National Fund for Scientific Research. Financial support from the Spanish Ministry of Economy and Competition under the project ECO2012-35820 is gratefully acknowledged.

\section{Appendix}

\section{Proof of Proposition 1.}

Take any path $\left\{i_{1}, i_{2}, \ldots, i_{k}, i_{k+1}, \ldots, i_{l}\right\}$ in $g$ between player $i$ and player $j$ with $i_{1}=i$ and $i_{l}=j$. Applying the equal bargaining power property for farsighted players, we have that

$$
\begin{aligned}
y_{i_{1}}(g, v) & =y_{i_{1}}\left(z_{i_{1}}(g), v\right)-y_{i_{2}}\left(z_{i_{2}}(g), v\right)+y_{i_{2}}(g, v) \\
& =\Delta_{i_{1} i_{2}}\left(z_{i_{1}}(g), z_{i_{2}}(g), v\right)+y_{i_{2}}(g, v),
\end{aligned}
$$

where $\Delta_{i_{1} i_{2}}\left(z_{i_{1}}(g), z_{i_{2}}(g), v\right)$ is the difference between player $i_{1}$ 's allocation at her bargaining threat and player $i_{2}$ 's allocation at his bargaining threat. Applying the equal bargaining power property for farsighted players, we have also that

$$
\begin{aligned}
y_{i_{2}}(g, v) & =y_{i_{2}}\left(z_{i_{2}}(g), v\right)-y_{i_{3}}\left(z_{i_{3}}(g), v\right)+y_{i_{3}}(g, v) \\
& =\Delta_{i_{2} i_{3}}\left(z_{i_{2}}(g), z_{i_{3}}(g), v\right)+y_{i_{3}}(g, v) .
\end{aligned}
$$

Hence,

$$
y_{i_{1}}(g, v)=\Delta_{i_{1} i_{2}}\left(z_{i_{1}}(g), z_{i_{2}}(g), v\right)+\Delta_{i_{2} i_{3}}\left(z_{i_{2}}(g), z_{i_{3}}(g), v\right)+y_{i_{3}}(g, v) .
$$

Notice that $\Delta_{i_{k} i_{k+1}}\left(z_{i_{k}}(g), z_{i_{k+1}}(g), v\right)=-\Delta_{i_{k+1} i_{k}}\left(z_{i_{k+1}}(g), z_{i_{k}}(g), v\right)$. Iterating this reasoning, we obtain

$$
\begin{aligned}
y_{i_{1}}(g, v) & =\sum_{k=1}^{k=l-1} \Delta_{i_{k} i_{k+1}}\left(z_{i_{k}}(g), z_{i_{k+1}}(g), v\right)+y_{i_{l}}(g, v) \\
& =y_{i_{1}}\left(z_{i_{1}}(g), v\right)-y_{i_{l}}\left(z_{i_{l}}(g), v\right)+y_{i_{l}}(g, v) .
\end{aligned}
$$

Hence,

$$
y_{i}(g, v)=y_{i}\left(z_{i}(g), v\right)-y_{j}\left(z_{j}(g), v\right)+y_{j}(g, v) .
$$


Summing up for all $j \in S(j \neq i)$ such that $S \in \Pi(g)$ and $i \in S$, we have

$$
(\# S-1) y_{i}(g, v)=(\# S-1) y_{i}\left(z_{i}(g), v\right)+\sum_{j \in S \in \Pi(g), j \neq i}\left(y_{j}(g, v)-y_{j}\left(z_{j}(g), v\right)\right) \text {. }
$$

Since $y$ satisfies the component efficiency property, i.e. $\sum_{j \in S \in \Pi(g)} y_{j}(g, v)=v(S, g)$, we have that

$$
(\# S) y_{i}(g, v)=(\# S-1) y_{i}\left(z_{i}(g), v\right)+v(S, g)-\sum_{j \in S \in \Pi(g), j \neq i} y_{j}\left(z_{j}(g), v\right) .
$$

Hence,

$$
y_{i}(g, v)=y_{i}\left(z_{i}(g), v\right)+\frac{1}{\# S}\left(v(S, g)-\sum_{j \in S \in \Pi(g)} y_{j}\left(z_{j}(g), v\right)\right) .
$$

\section{Proof of Proposition 4.}

Suppose that $y$ is anonymous and component efficient and $v$ is anonymous, component additive and top convex. We will show that there is no von NeumannMorgenstern farsightedly stable set with bargaining $G \neq E(v)$.

(i) Take any $G$ such that $G \cap E(v)=\emptyset$ and $G$ is von Neumann-Morgenstern farsightedly stable set with bargaining.

(ia) Suppose that $G=\{g\}$. Anonymity of $v$ and $y$ imply equal sharing of the value of the complete network. Hence, if $g$ is the complete network, then equal bargaining power and consistency imply that, in any $g^{\prime} \neq g$, members of each component share equally the value of each component. If $g$ is not the complete network, then equal bargaining power and consistency imply that members of each component of $g$ share equally the value of the component. Then, top convexity of the value function implies that $g \notin F\left(g^{\prime \prime}\right)$ for all $g^{\prime \prime} \in E(v)$ (any $g^{\prime \prime} \in E(v)$ Pareto dominates all $\left.g^{\prime} \notin E(v)\right)$. Hence, $G$ fails to satisfy external stability and we have a contradiction.

(ib) Suppose that $\# G>1$. Internal stability for $G$ implies that players obtain the same allocation in any $g \in G$. Then, equal bargaining power and consistency imply that, in any $g^{\prime} \notin G$, members of each component share equally the value of each component. Furthermore, top convexity of the value function implies that $g \notin F\left(g^{\prime \prime}\right)$ for all $g^{\prime \prime} \in E(v)$ and $g \in G$. Hence, $G$ fails to satisfy external stability and we have a contradiction. 
(ii) Take $G$ such that $G \cap E(v) \neq \emptyset, G \neq E(v)$ and $G$ is von Neumann-Morgenstern farsightedly stable set with bargaining.

(iia) Suppose that $G=\{g\}$. Notice that $g$ is a strongly efficient network, $g \in E(v)$. Anonymity of $v$ and $y$ imply equal sharing of the value of the complete network. Hence, if $g$ is the complete network, then equal bargaining power and consistency imply that, in any $g^{\prime} \neq g$, members of each component share equally the value of each component. If $g$ is not the complete network, then equal bargaining power and consistency imply that members of each component of $g$ share equally the value of the component. Top convexity implies that all components of a strongly efficient network must lead to the same per-capita value (if some component led to a lower per capita value than the average, then another component would have to lead to a higher per capita value than the average which would contradict top convexity). Then, since $G=\{g\} \varsubsetneqq E(v)$, there is $g^{\prime \prime} \in E(v), g^{\prime \prime} \neq g$, such that $g \notin F\left(g^{\prime \prime}\right)$. Hence, $G$ fails to satisfy external stability and we have a contradiction.

(iib) Suppose that $\# G>1$. First, consider the case $G \nsupseteq E(v)$. Internal stability for $G$ implies that players obtain the same allocation in any $g, g^{\prime} \in G$, but this is not possible since by top convexity $g \in G \cap E(v)$ Pareto dominates $g^{\prime} \in G \backslash E(v)$. Hence, $G$ fails to satisfy internal stability and we have a contradiction. Second, consider the case $G \varsubsetneqq E(v)$. Internal stability for $G$ implies that players obtain the same allocation in any $g \in G$, and is satisfied since $v$ is top convex. Then, equal bargaining power and consistency imply that, in any $g^{\prime} \notin G$, members of each component share equally the value of each component. But there is $g^{\prime} \notin G$ such that $g^{\prime} \in E(v)$. Top convexity of the value function implies that there is no $g \in G$ such that $g \in F\left(g^{\prime}\right)$ for any $g^{\prime} \notin G, g^{\prime} \in E(v)$. Hence, $G$ fails to satisfy external stability and we have a contradiction. Third, consider the case $G \nsupseteq E(v)$ and $G \nsubseteq E(v)$. Similar arguments lead to a contradiction.

Thus, if $y$ is anonymous and component efficient and $v$ is anonymous, component additive and top convex, then $E(v)$ is the unique von Neumann-Morgenstern farsightedly stable set with bargaining and the endogenously determined allocation rule is the componentwise egalitarian allocation rule.

\section{Proof of Proposition 6.}

Take any anonymous, component additive and top convex value function $v$ such that $E(v)$ consists only of componentwise symmetric networks. Suppose $y$ is component efficient and anonymous. We will show that $E(v)$ is a pairwise farsightedly stable set with bargaining if and only if $y$ is the componentwise egalitarian allocation 
rule.

$(\Rightarrow)$

Suppose $E(v)$ is a pairwise farsightedly stable set with bargaining. Since $y$ is anonymous and component efficient and $E(v)$ consists only of componentwise symmetric networks, there is equal sharing of the value of each component among the members of the component for each $g \in E(v)$. Top convexity implies that all components of any $g \in E(v)$ have the same per-capita value, and that all components of any $g^{\prime}$ such that $g^{\prime} \notin E(v)$ have a lower per-capita value than the per-capita value of any component of any $g \in E(v)$. Component efficiency, equal bargaining power and consistency imply that there is equal sharing of the value of each component among the members of the component for each $g^{\prime} \notin E(v)$. Hence, $y$ is the componentwise egalitarian allocation rule.

$(\Leftarrow)$ From Proposition 1 in Grandjean, Mauleon and Vannetelbosch (2011).

\section{Proof of Proposition 7.}

Take any value function $v$ that satisfies anonymity and strong critical-link monotonicity. Navarro (2013b) has shown that if $v$ satisfies strong critical-link monotonicity, then the complete network $g^{N}$ is the unique strongly efficient network. Suppose $y$ is component efficient and anonymous. We will show that $E(v)=\left\{g^{N}\right\}$ is a von Neumann-Morgenstern farsightedly stable set with bargaining if and only if $y$ is the componentwise egalitarian allocation rule.

$(\Rightarrow)$

Suppose $E(v)=\left\{g^{N}\right\}$ is a von Neumann-Morgenstern farsightedly stable set with bargaining. Since $y$ is anonymous and component efficient and $E(v)$ consists only of the complete network, there is equal sharing of the value of the complete network among all players. Component efficiency, equal bargaining power and consistency imply that there is equal sharing of the value of each component among the members of the component for each $g^{\prime} \notin E(v)$. Hence, $y$ is the componentwise egalitarian allocation rule.

$(\Leftarrow)$

Take any anonymous and strong critical-link monotonic value function $v$. Suppose that $y$ is the componentwise egalitarian allocation rule. Since $E(v)=\left\{g^{N}\right\}$ it follows that $v\left(g^{N}\right) / \# N>v(g) / \# N$ for any $g \neq g^{N}$ such that $\Pi(g)=\{N\}$. Strong critical-link monotonicity implies that under the componentwise egalitarian allocation rule the strongly efficient network $g^{N}$ Pareto dominates all $g^{\prime} \neq g^{N}$. Then, it is immediate that $F(g)=\emptyset$ for $g^{N}$ [Internal stability] and that $F\left(g^{\prime}\right) \cap\left\{g^{N}\right\} \neq \emptyset$ for all 
$g^{\prime} \neq g^{N}$ [External stability]. Since $y$ is the componentwise egalitarian allocation rule, equal bargaining power for farsighted players is satisfied for $z$ such that $z_{i}(g)=g^{N}$ [Equal bargaining power]. In addition, $z$ such that $z_{i}(g)=g^{N}$ is consistent since $\left(F\left(g^{\prime}\right) \cup\left\{g^{\prime}\right\}\right) \cap\left\{g^{N}\right\} \neq \emptyset$ for all $g^{\prime} \neq g^{N}$ [Consistency]. Thus, $\left\{g^{N}\right\}$ satisfies internal stability, external stability, equal bargaining power and consistency. It is the unique von Neumann-Morgenstern farsightedly stable set with bargaining if $y$ is the componentwise egalitarian allocation rule because $F\left(g^{N}\right)=\emptyset$ and $F\left(g^{\prime}\right) \cap\left\{g^{N}\right\} \neq \emptyset$ for all $g^{\prime} \neq g^{N}$.

\section{References}

[1] BLOCH, F., and M.O. JACKSON (2007), The formation of networks with transfers among players, Journal of Economic Theory 133, 83-110.

[2] CHWE, M.S. (1994) Farsighted coalitional stability, Journal of Economic Theory 63, 299-325.

[3] CURRARINI, S., and M. MORELLI (2000) Network formation with sequential demands, Review of Economic Design 5, 229-249.

[4] DUTTA, B., S. GHOSAL, and D. RAY (2005) Farsighted network formation, Journal of Economic Theory 122, 143-164.

[5] GOYAL, S. (2007) Connections: An Introduction to the Economics of Networks. Princeton: Princeton University Press.

[6] GRAndjEAN, G., A. MAUlEON, and V. VANNETELBOSCH (2011) Connections among farsighted agents, Journal of Public Economic Theory 13, 935955 .

[7] HERINGS, P. J. J., A. MAULEON, and V. VANNETELBOSCH (2004) Rationalizability for social environments, Games and Economic Behavior 49, 135156 .

[8] HERINGS, P. J. J., A. MAULEON, and V. VANNETELBOSCH (2009) Farsightedly stable networks, Games and Economic Behavior 67, 526-541.

[9] JACKSON, M. O. (2003) The stability and efficiency of economic and social networks, in Networks and Groups: Models of Strategic Formation, B. Dutta and M. O. Jackson, eds. Heidelberg: Springer-Verlag. 
[10] JACKSON, M. O. (2005) Allocation rules for network games, Games and Economic Behavior 51, 128-154.

[11] JACKSON, M. O. (2008) Social and Economic Networks. Princeton: Princeton University Press.

[12] JACKSON, M. O., and A. VAN DEN NOUWELAND (2005) Strongly stable networks, Games and Economic Behavior 51, 420-444.

[13] JACKSON, M. O., and A. WATTS (2002) The evolution of social and economic networks, Journal of Economic Theory 106, 265-295.

[14] JACKSON, M. O., and A. WOLINSKY (1996) A strategic model of social and economic networks, Journal of Economic Theory 71, 44-74.

[15] MATSUBAYASHI, N., and S. YAMAKAWA (2006) A note on network formation with decay, Economics Letters 93, 387-392.

[16] MAUlEON, A., V. VANNETELBOSCH, and W. VERGOTE (2011) Von Neumann-Morgenstern farsightedly stable matchings, Theoretical Economics 6, 499-521.

[17] MUTUSWAMI, S., and E. WINTER (2002) Subscription mechanisms for network formation, Journal of Economic Theory 106, 242-264.

[18] MYERSON, R.B. (1977) Graphs and cooperation in games, Mathematics of Operations Research 2, 225-229.

[19] NAVARRO, N. (2007) Fair allocation in networks with externalities, Games and Economic Behavior 58, 354-364.

[20] NAVARRO, N. (2010) Flexible network rules for identified externalities, Games and Economic Behavior 69, 401-410.

[21] NAVARRO, N. (2013a) Expected fair allocation in farsighted network formation, forthcoming in Social Choice and Welfare.

[22] NAVARRO, N. (2013b) Forward-looking pairwise stability in networks with externalities across components. Mimeo, IKERBASQUE.

[23] PAGE, F. H., Jr., M. WOODERS, and S. KAMAT (2005) Networks and farsighted stability, Journal of Economic Theory 120, 257-269. 
[24] PAGE, F. H., Jr., and M. WOODERS (2009) Strategic basins of attraction, the path dominance core, and network formation games, Games and Economic Behavior 66, 462-487.

[25] PEREZ-CASTRILlO, D., and D. WETTSTEIN (2005) Forming efficient networks, Economics Letters 87, 83-87.

[26] SLIKKER, M., and A. VAN DEN NOUWELAND (2000) A one stage model of link formation and payoff division, Games and Economic Behavior 34, 153-175.

[27] TERCIEUX, O., and V. VANNETELBOSCH (2006) A characterization of stochastically stable networks, International Journal of Game Theory 34, 351-369. 


\title{
Cahiers du GREThA Working papers of GREThA
}

\author{
GREThA UMR CNRS 5113 \\ Université Montesquieu Bordeaux IV \\ Avenue Léon Duguit \\ 33608 PESSAC - FRANCE \\ Tel : +33 (0)5.56.84.25.75 \\ Fax : +33 (0)5.56.84.86.47 \\ http://gretha.u-bordeaux.fr/
}

\begin{abstract}
Cahiers du GREThA (derniers numéros - last issues)
2013-17 : BECUWE Stéphane, BLANCHETON Bertrand, CHARLES Léo, First globalization: why did France miss the boat?

2013-18 : HARDY P.H., BENE C., DOYEN L., PEREAU J. C., MILLS D., Viability and resilience of smallscale fisheries through cooperative arrangements

2013-19 : BONNEFOND Céline, CLEMENT Matthieu, COMBARNOUS François, In search of the elusive Chinese urban middle class: An exploratory analysis

2013-20 : PASTUREAU Guillaume, JOURDHEUIL Romain, Le prêt sur gages au Crédit municipal : vers une analyse exploratoire des relations entre banquier social et emprunteur

2013-21 : BLANCHETON Bertrand, L'autonomie de la Banque de France au XXe siècle

2013-22 : MAVEYRAUD Samuel, La structure du réseau de commerce international en 1850

2013-23: BONNEFOND Céline, Growth dynamics and conditional convergence among Chinese provinces: a panel data investigation using system GMM estimator

2013-24 : SALLE Isabelle, SENEGAS Marc-Alexandre, YILDIZOGLU Murat, How Transparent About Its Inflation Target Should a Central Bank be? An Agent-Based Model Assessment

2013-25 : LUSTOSA J. Maria Cecilia, FAURE Yves-André, Changements institutionnels et politiques publiques au Brésil. Aux sources de la réduction des inégalités sociales, de la pauvreté et des disparités régionales

2014-01: BLANCHETON Bertrand, PASTUREAU Guillaume, Le Mont-de-Piété à Bordeaux, les raisons d'un succès (1802-1913)

2014-02 : FRIGANT Vincent, MIOLLAN Stéphane, La restructuration de la géographie de l'industrie automobile en Europe durant les années 2000

2014-03 : BLANCHETON Bertrand, Les improvisations financière de la guerre de 1914-1918 en France. Les enjeux de la liquidité.

2014-04 : ARNAUD Brice, Extended Producer Responsibility and Green Marketing: an Application to Packaging

2014-05: CARAYOL Nicolas, DELILLE Rémi, VANNETELBOSCH Vincent, Allocating value among farsighted players in network formation
\end{abstract}

La coordination scientifique des Cahiers du GREThA est assurée par Emmanuel PETIT. La mise en page est assurée par Anne-Laure MERLETTE. 